\title{
Influence of PLGA and PLGA-PEG on the dissolution profile of oxaliplatin
}

\author{
Emiliane Daher Pereira ${ }^{1}$, Renata Cerruti ${ }^{1}$, Edson Fernandes ${ }^{1}$, Luis Peña ${ }^{2}$, Vivian Saez ${ }^{1,2}$, José Carlos Pinto ${ }^{3}$, \\ José Angel Ramón ${ }^{1,2,3}$, Geiza Esperandio Oliveira ${ }^{1,4}$ and Fernando Gomes de Souza Júnior ${ }^{1,5 *}$ \\ ${ }^{1}$ Laboratório de Biopolímeros e Sensores, Instituto de Macromoléculas, \\ Universidade Federal do Rio de Janeiro - UFRJ, Rio de Janeiro, RJ, Brazil \\ ${ }^{2}$ Centro de Biomateriales, Universidad de La Habana, Havana, Cuba \\ 3Programa de Engenharia Química, Instituto Alberto Luiz Coimbra de Pós-graduação e \\ Pesquisa de Engenharia - COPPE, Universidade Federal do Rio de Janeiro - UFRJ, Rio de Janeiro, RJ, Brazil \\ ${ }^{4}$ Departamento de Química, Universidade Federal do Espírito Santo - UFES, Vitória, ES, Brazil \\ ${ }^{5}$ Programa de Engenharia Civil, Instituto Alberto Luiz Coimbra de Pós-graduação e \\ Pesquisa de Engenharia - COPPE, Universidade Federal do Rio de Janeiro - UFRJ, Rio de Janeiro, RJ, Brazil \\ *fgsj@ufrj.br
}

\begin{abstract}
Oxaliplatin was inserted into polymeric matrices aiming to study the interaction of this drug with these polymers and its capability to diffuse to the environment. Tested polymers were: (1) polyethylene glycol (PEG), (2) poly(lactic-co-glycolic acid) (PLGA), and (3) a copolymer of them (PLGA-PEG). The latter two were synthesized by us using polycondensation in bulk. Oxaliplatin was included in the matrices by the melt mixing process followed by casting. Fourier tran sform infrared spectroscopy (FTIR), proton nuclear magnetic resonance ( $\left.{ }^{1} \mathrm{H}-\mathrm{NMR}\right)$ and X-ray diffraction (DRX) studies of the polymers were performed proving the obtaining of the desired materials. In addition, the interaction between drug and matrices and the release profile of the oxaliplatin from these matrices were analyzed. Among them, PEG did not control the oxaliplatin release. In turn, PLGA and PLGA-PEG present drug release profiles quite similar. Oxaliplatin was completely released from PLGA and PLGA-PEG in 5 hours, by a relaxation mechanism. There was no evidence of oxaliplatin interaction with the different polymers. In addition, as the PEG improves the biocompatibility and biomasking, obtained results prove the obtaining of a drug release system, which allowed the total use of the drug improving the cancer treatment and even the welfare of the patients.
\end{abstract}

Keywords: oxaliplatin, drug delivery, biodegradable polymer, PLGA-PEG, block copolymer.

\section{Introduction}

More than 10 million people are diagnosed with cancer annually, making this disease a leading cause of death. Furthermore, new projections allow predicting that by 2020 , there will be 15 million new cases of cancer every year ${ }^{[1,2]}$. Nowadays, the third most common cancer worldwide is the colorectal cancer and this is also the fourth most common cause of death ${ }^{[3-6]}$.

Oxaliplatin is a third-generation platinum-based chemotherapeutic agent, which presents a remarkable success on the cancer treatment, as the other platinum-based drugs, such as cisplatin and carboplatin ${ }^{[7]}$. Specifically, oxaliplatin is a organoplatinum compound with significant activity against advanced or metastatic digestive tumors, mainly colorectal ones ${ }^{[8]}$. Therefore, oxaliplatin is considered one of the first-line drugs in the treatment of advanced colorectal cancer ${ }^{[9-12]}$. In addition, oxaliplatin does not induce nephrotoxicity to the same extent as these other platinum-based drugs ${ }^{[13]}$. On the other hand, recent reports criticize the oxaliplatin use due to some cases of peripheral neuropathy caused by cumulative doses of this drug ${ }^{[13,14]}$.

Drugs entrapped into biodegradable and biocompatible polymeric matrices have been successfully employed for the controlled release of drugs ${ }^{[15-19]}$. Potentially, these systems are able to maintain drug concentrations within therapeutic ranges even along days. Consequently, it may diminish side effects caused by high concentrations and repeated administrations, and improve patient compliance as compared to conventional regimens ${ }^{[20]}$. Poly(lactic-co-glycolic acid) (PLGA) copolymers ${ }^{[21]}$ have been extensively used in drug delivery systems (DDS) as alternative to improve conventional formulations ${ }^{[21-23]}$. These DDSs allow extended and controlled releases of drugs dispersed into the polymer ${ }^{[24]}$. However, PLGA hydrophobicity may be a problem for some drugs. Incomplete release is usual if drugs have interactions with them $^{[25]}$. The attaching of PEG chains to PLGA may solve these situations ${ }^{[26,27]}$. The inclusion of PEG into material could also be convenient for improving biocompatibility of the systems ${ }^{[28]}$. However, high solubility of PEG could accelerate the drug release rate which in some cases it is an undesirable effect.

In this paper, the effect of the hydrophilicity of the polymeric matrix on the release profiles of oxaliplatin was studied. In addition, possible interactions between the drug and the matrices were investigated. As expected, PEG did not 
act as a release controlling matrix for oxaliplatin. However it is possible to exploit the biocompatibility provided by the PEG as part of PLGA-PEG copolymer because its presence does not change the drug release profile. Oxaliplatin was completely released from both PLGA and PLGA-PEG in five hours.

\section{Experimental Part}

\subsection{Materials}

PEG (Mn 6000) was purchased from SIGMA-ALDRICH, Brazil. The oxaliplatin was gently provided by Center for Research and Development of Medicine, Havana, Cuba. All others chemical used were purchased from VETEC, Brazil. All chemical materials were used as received.

\subsection{Synthesis of block copolymers}

The PLGA block copolymer was synthesized by polycondensation in bulk from lactic acid $(50 \mathrm{ml})$ and glycolic acid $(62 \mathrm{ml})$ in equimolar ratio (1:1). Sulfuric acid $(98 \% \mathrm{v} / \mathrm{v}, 0.25 \mathrm{~mL})$ was added as catalyst, in a closed system under nitrogen atmosphere and slight vacuum. Temperature was kept at $140^{\circ} \mathrm{C}$ under magnetic stirring for $10 \mathrm{~h}^{[29]}$. The PLGA-PEG block copolymer was synthesized following the same procedure, with addition of commercial PEG $(5 \mathrm{~g})^{[27]}$.

\subsection{Preparation of polymer/drug systems}

The three polymers (PEG; PLGA; PLGA-PEG) were molten separately at $120^{\circ} \mathrm{C}$. This temperature was chosen since it is considerably lower than the degradation temperature of the drug which is $400^{\circ} \mathrm{C}$ according to the results of the TGA analysis. Oxaliplatin was incorporated in the three polymers in a $1 \% \mathrm{w} / \mathrm{w}$ concentration by melting at $120^{\circ} \mathrm{C}$ inside a $50 \mathrm{~mL}$ reactor using mechanical stirring and dry $\mathrm{N}_{2(\mathrm{~g})}$ flow. After the drug incorporation, melted mixture was casted, producing disks (diameter: $1.0 \mathrm{~cm}$; height: $0.5 \mathrm{~cm}$ ). The DDS prepared were named as PEGO, PLGAO and PLGA-PEGO, respectively.

\subsection{Materials characterization}

Hydrogen nuclear magnetic resonance ( $\left.{ }^{1} \mathrm{H}-\mathrm{NMR}\right)$ and Fourier transform infrared (FT-IR) were used to study the composition of the copolymers. Samples were dissolved in $\mathrm{CDCl}_{3}$ and their ${ }^{1} \mathrm{H}$ NMR spectra were recorded on a $\operatorname{Varian}^{\circledR}$ equipment model Oxford 300. FTIR spectra were obtained from neat films cast from the chloroform sample solutions on $\mathrm{KBr}$ tablets, with a Varian equipment model 3100 FTIR Excalibur Series, using a resolution of $4 \mathrm{~cm}^{-1}$ and 20 scans from 4000 to $400 \mathrm{~cm}^{-1}$.

X-Ray Diffraction (XRD) was also used to characterize the copolymers, the samples prepared and the drug. The equipment used was a Rigaku Miniflex X-ray diffractometer in a $2 \theta$ range from $2^{\circ}$ to $80^{\circ}$ by the method FT (fixed time). The steps were equal to $0.05 \% \mathrm{~s}$, using a tube voltage and current equal to $30 \mathrm{kV}$ and $15 \mathrm{~mA}$, respectively. The radiation used was $\mathrm{CuK} \alpha=1.5418 \AA$.

\subsection{Presence of oxaliplatin in matrices}

The technique of least squares was used to compare the FTIR data obtained from the DDS containing oxaliplatin with the one of matrices without the drug. Specifically, the coefficient of determination $\left(\mathrm{R}^{2}\right)$ and the root mean square error (RMSE) were used as indicatives of the presence of oxaliplatin into the matrices. This test was reported by our group elsewhere ${ }^{[30]}$.

\subsection{Dissolution test of oxaliplatin}

For each test, one gram of PEGO, PLGAO and PLGA-PEGO was studied using the USP Apparatus I at $75 \mathrm{rpm}$. First, the released amount of the drug was analyzed in $\mathrm{HCl} 0.1 \mathrm{M}$ (900 $\mathrm{ml}$ ) by one hour. Soon afterwards, this solution was substituted by the same volume of phosphate buffer $\mathrm{pH} 7.8$ and drug elution was determined by other 4 hours. Samples were collected at $0.25 \mathrm{~h} ; 0.5 \mathrm{~h} ; 1 \mathrm{~h} ; 1.25 \mathrm{~h} ; 1.5 \mathrm{~h} ; 2 \mathrm{~h} ; 3 \mathrm{~h} ; 4 \mathrm{~h}$ and $5 \mathrm{~h}$. All these tests were performed in triplicate.

Ultraviolet-visible spectrophotometry (UV-Vis) was used to quantify the oxaliplatin in the samples. The measurements were performed at $260 \mathrm{~nm}$ using a monochromator Biospectro spectrophotometer model SP-220. The spectra of the solutions with known concentrations of oxaliplatin were collected and used to set up an analytical curve.

\section{Results and Discussion}

Figure 1 shows the ${ }^{1} \mathrm{H}-\mathrm{NMR}$ spectrum of the PLGA copolymer. The peak at $1.5 \mathrm{ppm}$ is associated with the repetitive methyl groups of the lactic acid. The peaks at $5.2 \mathrm{ppm}$ and $4.8 \mathrm{ppm}$ are related to the $\mathrm{CH}-\mathrm{CH}_{3}$ from lactic acid and $\mathrm{CH}-\mathrm{H}$ from glycolic acid, respectively, confirming the synthesis of the copolymer ${ }^{[27,29]}$. The molar amount of each comer of the copolymer was calculated using the relationship among the peak areas and the number of $\mathrm{H}$ atoms. The synthesized copolymer presented $46.6 \mathrm{~mol} \%$ of their molar mass related to the glycolate comer, while the lactate comer corresponded to $53.4 \mathrm{~mol} \%$ of the copolymer.

Figure 2 shows the ${ }^{1} \mathrm{H}-\mathrm{NMR}$ spectrum of the PLGA-PEG copolymer. In this spectrum, same peaks of PLGA are present

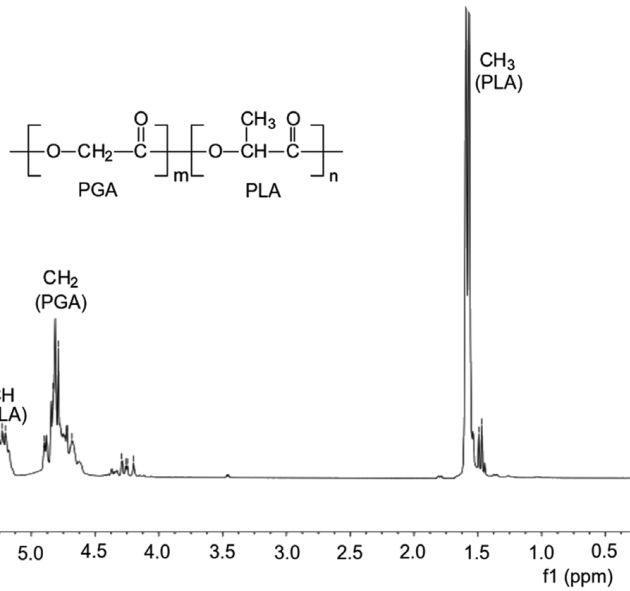

Figure 1. ${ }^{1} \mathrm{H}-\mathrm{NMR}$ spectrum of the PLGA copolymer. 
and the new peak at $3.64 \mathrm{ppm}$ is assigned to the methylene groups present in $\mathrm{PEG}^{[27,31-33]}$. Again, the peak areas were used to estimate the molar amount of PEG in the system PLGA-PEG. Calculated value is around $5.9 \mathrm{~mol} \%$, while the molar mass related to the glycolate and lactate comers corresponds to $45.7 \mathrm{~mol} \%$ and $48.4 \mathrm{~mol} \%$, respectively.

FTIR spectra of PEG, PLGA and PLGA-PEG are shown in Figure 3. The FTIR spectrum shown in Figure 3a corresponds to PEG. The smooth wide band around $3500 \mathrm{~cm}^{-1}$ is related to the oxygen atom able to form hydrogen bonds. The characteristic band at $2888 \mathrm{~cm}^{-1}$ is attributed to the stretching of $\mathrm{CH}, \mathrm{CH}_{2}$ and $\mathrm{CH}_{3}$ groups. The characteristic bands at 1464 and $1343 \mathrm{~cm}^{-1}$ are associated with the $\mathrm{C}-\mathrm{H}$ bending. The stretching of $\mathrm{C}-\mathrm{C}-\mathrm{O}$ group appears at 1280 and $1100 \mathrm{~cm}^{-1}$. The later characteristic band is conjugated with the C-O-C group. The harmonic bands of C-C-O group appear around 950 and $840 \mathrm{~cm}^{-1}$. The spectrum shown in Figure $3 \mathrm{~b}$ corresponds to PLGA copolymer, again is possible to see a smooth wide band around $3500 \mathrm{~cm}^{-1}$ related to the oxygen capability to form hydrogen bonds. The small doublet around $3000 \mathrm{~cm}^{-1}$ is related to $\mathrm{CH}$, $\mathrm{CH}_{2}$ and $\mathrm{CH}_{3}$ groups. The characteristic peak at 1752 $\mathrm{cm}^{-1}$ is attributed to the stretching of the $\mathrm{C}=\mathrm{O}$. While the characteristic band at $1182 \mathrm{~cm}^{-1}$ can be assigned to the ether group. The characteristic bands at $1130 \mathrm{~cm}^{-1}$ and $1452 \mathrm{~cm}^{-1}$ are attributed to $\mathrm{C}-\mathrm{O}-\mathrm{C}$ group and $\mathrm{C}-\mathrm{H}$ bond of the methyl group, respectively ${ }^{[32,34-37]}$. The Figure $3 \mathrm{c}$ shows the PLGAPEG spectrum. The spectrum profile is very similar to the PLGA one, which can be explained by the small amount of PEG in the system, around $5.9 \mathrm{~mol} \%$. As showed by the spectra, the PLGA characteristic bands are stronger than PEG, since the former corresponds to more than $90 \%$ of the block copolymer. Therefore, the PEG presence can be barely noticed by the small signal of the C-C-O harmonics, placed around 950 and $840 \mathrm{~cm}^{-1}$.

The FTIR spectra of oxaliplatin and the samples PEGO, PLGAO, PLGA-PEGO are showed in Figure 4. In the spectrum of oxaliplatin (Figure 4a), the peaks at 3264 and $3509 \mathrm{~cm}^{-1}$ confirm the presence of an $\mathrm{NH}$ stretch, and peak at $812 \mathrm{~cm}^{-1}$ shows $\mathrm{N}-\mathrm{H}$ bending; $\mathrm{C}=\mathrm{O}$ stretch was observed at $1707 \mathrm{~cm}^{-1}$. In spectra of matrices combined with oxaliplatin (Figure 4b, 4c and 4d), signals corresponding to drug were not observed, maybe due to its low concentration in the mixtures ${ }^{[38]}$.

Due to small differences among the FTIR spectra of the matrices in comparison to the ones containing oxaliplatin, the RMSE statistical tool was used to prove the presence of the drug in the materials. These differences can be expressed using appropriate statistical tools. Among them, the root mean squared error (RMSE) is very useful to study the misfit between experimental data and mode ${ }^{[30,39]}$. Therefore, RMSE was calculated through linear regressions between absorbances of the matrix and analogous filled with oxaliplatin, using the least squares approach ${ }^{[40]}$. The obtained results are shown in Figure 5. As reference, absorbance of the PLA was plotted as a function of its own absorbance and RMSE is, obviously, equal to zero. In turn, absorbances of PEGOxPEG, PLGAOxPLGA and PLGA-PEGOxPLGA-PEG produced RMSE values equal to $4.79,3.27$ and 3.11 , respectively. In spite observed differences, probably produced by the chemical differences among tested materials, all of these results were obtained with $\mathrm{p}<0.05$, indicating that matrices were successfully loaded with oxaliplatin.

Figure 6 shows the XRD analysis for polymers and DDS. The diffractogram of PEG (Figure 6a) exhibits two peaks indicative of crystallinity: $19.2^{\circ}(2 \theta)$ and $23.4^{\circ[41]}$. The diffractogram of pure oxaliplatin (see Figure $6 \mathrm{~d}$ ) exhibits many characteristic peaks due to its crystalline nature $^{[38]}$. The diffractograms of PLGAO and PLGA-PEGO (see Figure 6f and g), respectively) show amorphous halos of the copolymer and the characteristic peaks of the drug. In turn, the XRD of the PLGA-PEG (Figure 6c) also shows only amorphous halos due the low proportion of the PEG in the copolymer (3.5\%) and PLGA (Figure 6 (b)) presents only amorphous halos which are in agreement with the literature $^{[34]}$

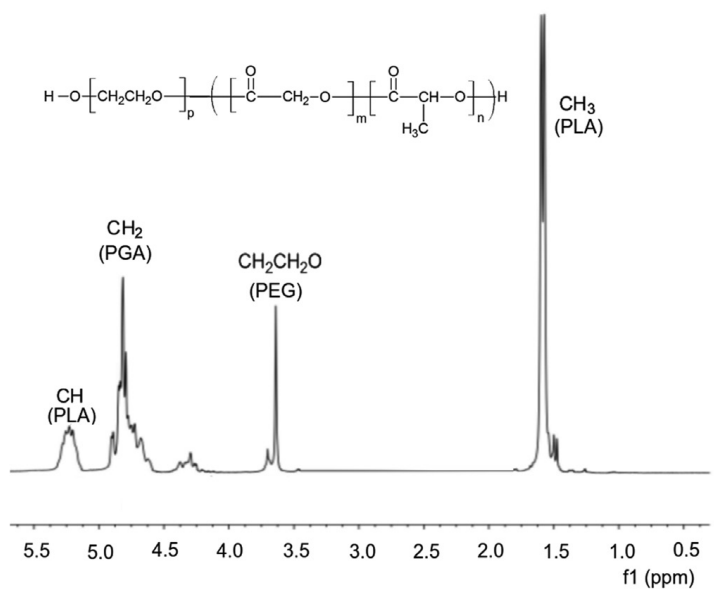

Figure 2. ${ }^{1} \mathrm{H}-\mathrm{NMR}$ spectrum of the PLGA-PEG copolymer

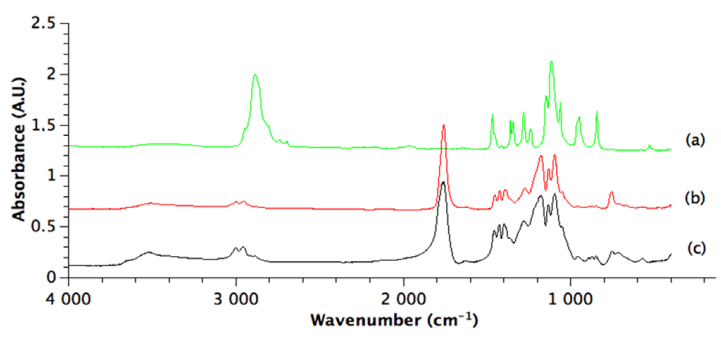

Figure 3. FTIR spectra of PEG (a), PLGA (b) and PLGA-PEG (c).

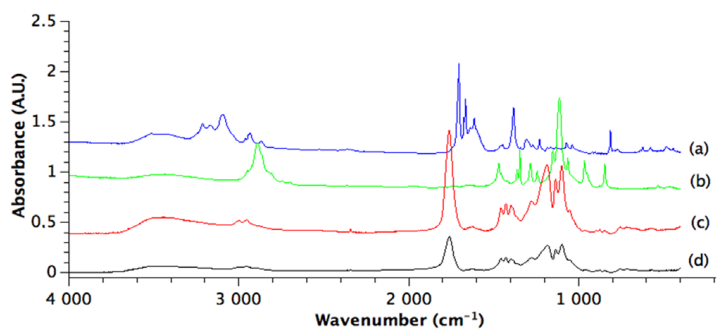

Figure 4. FTIR spectra of oxaliplatin (a), PEGO (b), PLGAO (c) and PLGA-PEGO (d). 


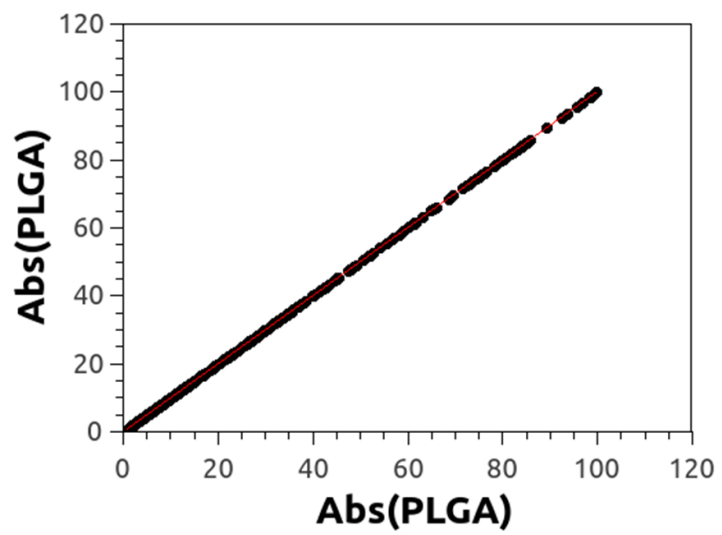

(a)

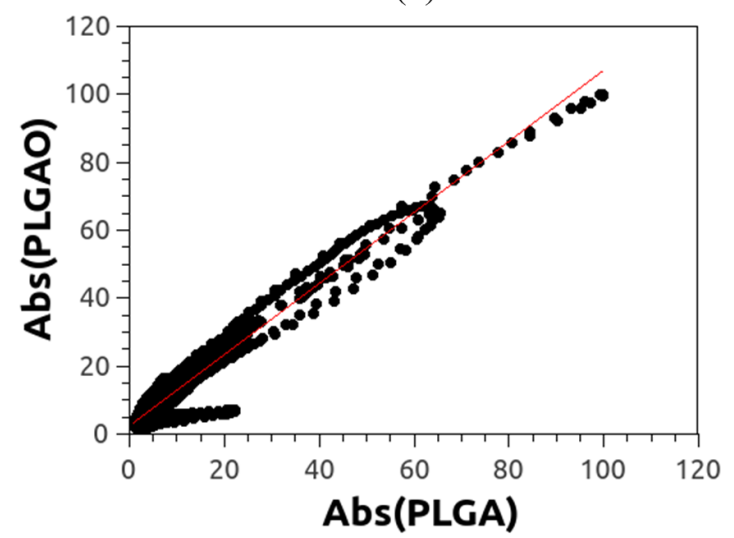

(c)

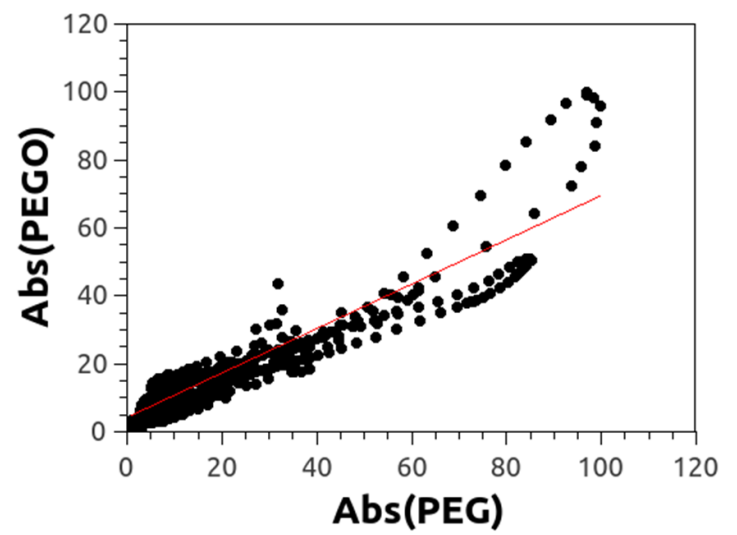

(b)

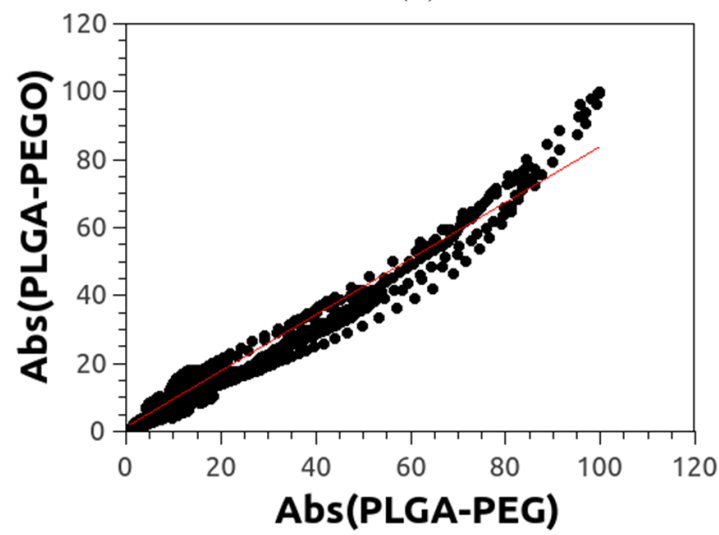

(d)

Figure 5. Comparison between normalized absorbances of oxaliplatin-loaded systems and non-loaded copolymers. PLGA vs PLGA (a), PEGO vs PEG (a), PLGAO vs PLGA (b) and PLGA-PEGO vs PLGA-PEG (d).

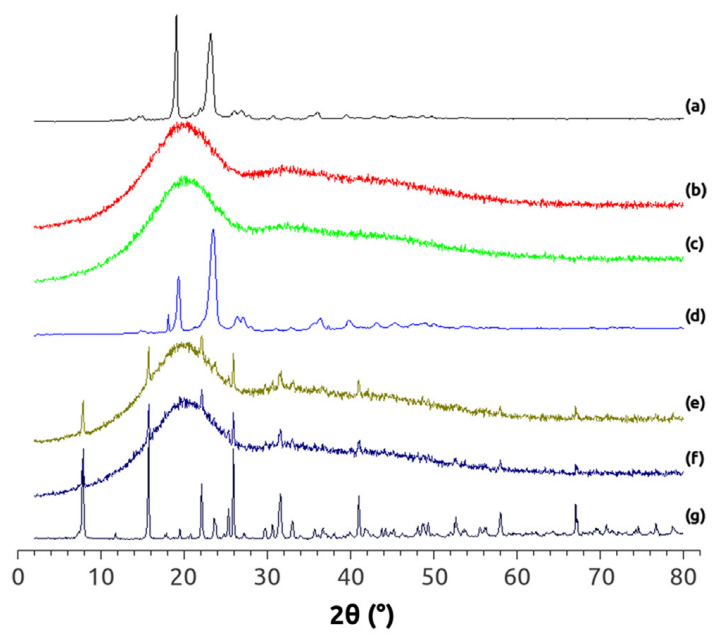

Figure 6. X-ray diffraction patterns of PEG (a), PLGA (b), PLGA-PEG (c), PEGO (d), PLGAO (e), PLGA-PEGO (f) and pure oxaliplatin $(\mathrm{g})$.

Dissolution tests of oxaliplatin-loaded DDS were monitored by UV-Vis analysis. Results are shown in Figure 7. Total drug release from PEG matrix (Figure 7a) took place in one hour due to its high hydrophilic character. The PLGA (Figure 7b) and PLGA-PEG (Figure 7c) matrices control effectively the release rate of oxaliplatin, which was completely delivered in five hours. At the end of study disks were completely degraded. The experimental data corresponding to these samples was fitted using the model presented in the Equation 1:

$$
R A O=\frac{A_{1}-A_{2}}{1+e^{\left(x-x_{0}\right) / d x}}+A_{2}
$$

In Equation 1, RAO is the released amount of oxaliplatin, $A_{1}$ is the lower $R A O$ limit, $A_{2}$ is the higher $R A O$ limit, $x_{0}$ is the inflexion (half amplitude) point and $d x$ is the width.

Results are showed in Table 1. All the parameters are statistically equal, confirming that oxaliplatin is released from PLGA and PLGA-PEG matrices in the same way.

The knowledge about the drug release mechanism and release rates is very important for programming the characteristics of the systems. Consequently, mathematical modeling of drug release processes from polymeric matrices plays an important role to predict the behavior of the system and to determine the structural parameters of the polymer that affect and control the drug release profiles. The drug release can occur through a pure Fickian diffusion, by 
Table 1. Parameters of the dissolution curves of oxaliplatin released from PLGA and PLGA-PEG matrices.

\begin{tabular}{ccccc}
\hline Sample & $\mathbf{A}_{\mathbf{1}}$ & $\mathbf{A}_{\mathbf{2}}$ & $\mathbf{d x}$ & $\mathbf{R}_{\mathbf{0}}$ \\
\hline PLGAO & $(-0.7 \pm 1.1) \times 10^{1}$ & $(1.01 \pm 0.05) \times 10^{2}$ & $(6 \pm 2) \times 10^{-1}$ & $(1.7 \pm 0.1) \times 10^{0}$ \\
PLGA-PEGO & $(-0.9 \pm 1.1) \times 10^{1}$ & $(9.9 \pm 0.5) \times 10^{1}$ & $(5 \pm 2) \times 10^{-1}$ & $(1.7 \pm 0.1) \times 10^{0}$ \\
\hline
\end{tabular}

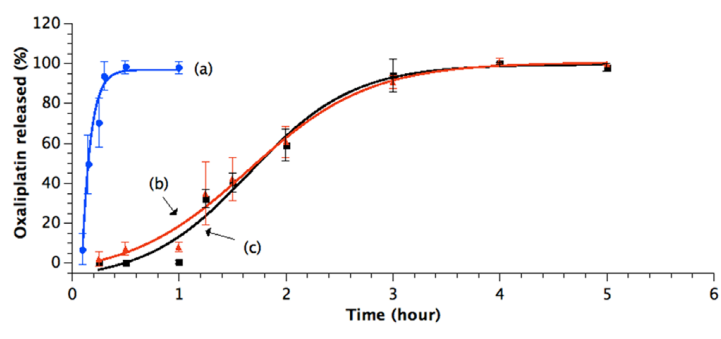

Figure 7. Oxaliplatin released along experimental time (first hour $\mathrm{HCl} 0.1 \mathrm{M}$ and last 4 hours with phosphate buffer): system PEGO (a); system PLGAO (b) and system PLGA-PEGO (c).

processes of relaxation and sometimes a combination of these two mechanisms takes place ${ }^{[42]}$. When the semi-empirical equation of Ritger-Peppas, ${ }^{[43]}$, is used for fitting the experimental data, the diffusional exponent $(n)$ indicates the mechanism for drug transport. An exponent value for cylindrical geometric $n=0.45$ indicates Fickian diffusion, $n$ within $0.45-0.89$ indicates the anomalous transport, $n=0.89$ indicates case II transport and $n$ more than 0.89 indicates super case II transport. An anomalous transport $(0.45<n<0.89)$ is referred to a drug transport by diffusion and relaxation of the polymer chains ${ }^{[43]}$.

The polymeric materials that controlled the release of oxaliplatin (PLGA and PLGA-PEG) have a value for $\mathrm{Tg}$ lower than the temperature for running the dissolution tests ${ }^{[44]}$. In that sense it is reasonable to suppose that drug transport could occur by a combination of both: diffusion and relaxation. Thus, for obtaining a preliminary idea of the release mechanism for oxaliplatin included in these disks, experimental data was fitted to theoretical release profiles given by a Peppas-Sahlin equation (Equation 2), which combines the Fickian diffusion and non-Fickian movement of drug molecules through polymer chains ${ }^{[45]}$.

$$
\frac{M_{t}}{M_{\infty}}=k_{1} t^{m}+k_{2} t^{2 m}
$$

In Equation 2, $k_{1}$ and $k_{2}$ are Fickian and relaxational contribution respectively ${ }^{[46]}$. They allow calculating the approximate contributions of the diffusional and relaxational mechanisms.

Experimental modeling was performed using the data from drug released until one hour, which corresponded to $60 \%$ of the total drug contained in DDS. The exponent $m$ was assumed equal to 0.44 due to geometry of the samples, which were disks. For PLGAO, $k_{1}$ was $-0.77 \pm 0.01$ and $k_{2}$ was $0.91 \pm 0.01$; for PLGA-PEGO, $k_{1}$ was $-0.93 \pm 0.02$ and $k_{2}$ was $1.05 \pm 0.02\left(\mathrm{R}^{2}\right.$ in both cases was greater than 0.99$)$. A negative value of $k_{1}$ was obtained in both cases, which can be considered as an insignificant effect of Fickian diffusion on drug release compared to the relaxation process. This result can be related to $\mathrm{Tg}$ of the polymers which are lower than $37^{\circ} \mathrm{C}$. In that sense when disks are placed into release fluid the combination of heating and the swelling in water could favor the polymer change from glassy to rubbery state. Consequently, in this case, relaxation of the polymer is the driving force for the release of oxaliplatin.

\section{Conclusions}

This work presented the release of oxaliplatin from PEG, PLGA and PLGA-PEG matrices. PLGA and PLGA-PEG were obtained by polycondensation and the synthesis of products was confirmed by $1 \mathrm{H}-\mathrm{NMR}$, FTIR and XRD. The release studies, monitored by ultraviolet analysis, showed that the PEG matrix cannot sustain the release for more than one hour, maybe due to the high solubility of this polymer. In contrast, the PLGA and PLGA-PEG copolymers release oxaliplatin during 5 hours in a similar way. So, the modification of PLGA using PEG did not modify oxaliplatin release. In addition, the characterization of materials by FTIR and the complete release of oxaliplatin from DDS allow believing that there are not interactions between drug and copolymers while the release mechanism seems to be due to relaxation of the polymer chains. Therefore, the PLGA-PEG copolymers could be preferred for designing controlled release systems for oxaliplatin with enhanced biomasking and biocompatibility.

\section{Acknowledgements}

The authors thank to Conselho Nacional de Desenvolvimento Científico e Tecnológico (CNPq-474940/2012-8 and 550030/2013-1), Coordenação de Aperfeiçoamento de Pessoal de Nível Superior (CAPES and CAPES-NANOBIOTEC), Financiadora de Estudos e Projetos (FINEP PRESAL Ref.1889/10) and Fundação Carlos Chagas Filho de Amparo à Pesquisa do Estado do Rio de Janeiro (FAPERJ) for the financial support and scholarships.

\section{References}

1. Parveen, S., \& Sahoo, S. (2011). Long circulating chitosan/ PEG blended PLGA nanoparticle for tumor drug delivery. European Journal of Pharmacology, 670(2-3), 372-383. http:// dx.doi.org/10.1016/j.ejphar.2011.09.023. PMid:21951969.

2. Pou, S. A., Osella, A. R., Eynard, A. R., Niclis, C., \& del Pilar Diaz, M. (2009). Colorectal cancer mortality trends in Córdoba, Argentina. Cancer Epidemiology, 33(6), 406-412. http://dx.doi. org/10.1016/j.canep.2009.09.009. PMid:19896430.

3. Nielsen, D., Palshof, J., Larsen, F., Jensen, B., \& Pfeiffer, P. (2014). A systematic review of salvage therapy to patients with metastatic colorectal cancer previously treated with fluorouracil, oxaliplatin and irinotecan $+/-$ targeted therapy. Cancer Treatment Reviews, 40(6), 701-715. http://dx.doi. org/10.1016/j.ctrv.2014.02.006. PMid:24731471. 
4. Baena, R., \& Salinas, P. (2015). Diet and colorectal cancer. Maturitas, 80(3), 258-264. http://dx.doi.org/10.1016/j. maturitas.2014.12.017. PMid:25619144.

5. Tong, L., Ahn, C., Symanski, E., Lai, D., \& Du, X. L. (2014). Temporal trends in the leading causes of death among a large national cohort of patients with colorectal cancer from 1975 to 2009 in the United States. Annals of Epidemiology, 24(6), 411-417. http://dx.doi.org/10.1016/j.annepidem.2014.01.005. PMid:24529646.

6. Wong, C. K., Chen, J., Yu, C. L., Sham, M., \& Lam, C. L. (2015). Systematic review recommends the European Organization for Research and Treatment of Cancer colorectal cancer-specific module for measuring quality of life in colorectal cancer patients. Journal of Clinical Epidemiology, 68(3), 266-278. http://dx.doi. org/10.1016/j.jclinepi.2014.09.021. PMid:25455838.

7. Johnstone, T. C. (2014). The crystal structure of oxaliplatin: a case of overlooked pseudo symmetry. Polyhedron, 67, 429-435. http://dx.doi.org/10.1016/j.poly.2013.10.003. PMid:24415827.

8. Zhou, Y., Wan, G., Spizzo, R., Ivan, C., Mathur, R., Hu, X., Ye, X., Lu, J., Fan, F., Xia, L., Calin, G. A., Ellis, L. M., \& $\mathrm{Lu}, \mathrm{X}$. (2014). miR-203 induces oxaliplatin resistance in colorectal cancer cells by negatively regulating ATM kinase. Molecular Oncology, 8(1), 83-92. http://dx.doi.org/10.1016/j. molonc.2013.09.004. PMid:24145123.

9. Wang, X. J., Li, Y., Luo, L., Wang, H., Chi, Z., Xin, A., Li, X., Wu, J., \& Tang, X. (2014). Oxaliplatin activates the Keap1/Nrf2 antioxidant system conferring protection against the cytotoxicity of anticancer drugs. Free Radical Biology \& Medicine, 70, 68-77. http://dx.doi.org/10.1016/j.freeradbiomed.2014.02.010. PMid:24556415.

10. Hu, C. J., Wang, B., Tang, B., Chen, B. J., Xiao, Y. F., Qin, Y., Yong, X., Luo, G., Zhang, J. W., Zhang, D., Li, S., He, F., \& Yang, S. M. (2015). The FOXM1-induced resistance to oxaliplatin is partially mediated by its novel target gene Mcl-1 in gastric cancer cells. Biochimica et Biophysica Acta, 1849(3), 290-299. http://dx.doi.org/10.1016/j.bbagrm.2014.11.008. PMid:25482013.

11. Janes, K., Wahlman, C., Little, J. W., Doyle, T., Tosh, D. K., Jacobson, K. A., \& Salvemini, D. (2015). Spinal neuroimmune activation is independent of T-cell infiltration and attenuated by $\mathrm{A} 3$ adenosine receptor agonists in a model of oxaliplatininduced peripheral neuropathy. Brain, Behavior, and Immunity, 44, 91-99. http://dx.doi.org/10.1016/j.bbi.2014.08.010. PMid:25220279.

12. Mehta, A. M., Van den Hoven, J. M., Rosing, H., Hillebrand, M. J., Nuijen, B., Huitema, A. D., Beijnen, J. H., \& Verwaal, V. J. (2015). Stability of oxaliplatin in chloride-containing carrier solutions used in hyperthermic intraperitoneal chemotherapy. International Journal of Pharmaceutics, 479(1), 23-27. http:// dx.doi.org/10.1016/j.ijpharm.2014.12.025. PMid:25535649.

13. Zedan, A. H., Hansen, T. F., Fex Svenningsen, A., \& Vilholm, O. J. (2014). Oxaliplatin-induced neuropathy in colorectal cancer: many questions with few answers. Clinical Colorectal Cancer, 13(2), 73-80. http://dx.doi.org/10.1016/j.clcc.2013.11.004. PMid:24365057.

14. Kanbara, T., Nakamura, A., Shibasaki, M., Mori, T., Suzuki, T., Sakaguchi, G., \& Kanemasa, T. (2014). Morphine and oxycodone, but not fentanyl, exhibit antinociceptive effects mediated by G-protein inwardly rectifying potassium (GIRK) channels in an oxaliplatin-induced neuropathy rat model. Neuroscience Letters, 280, 119-124. http://dx.doi.org/10.1016/j. neulet.2014.08.005. PMid:25128218.

15. Lu, Y., \& Chen, S. C. (2004). Micro and nano-fabrication of biodegradable polymers for drug delivery. Advanced Drug Delivery Reviews, 56(11), 1621-1633. http://dx.doi.org/10.1016/j. addr.2004.05.002. PMid:15350292.
16. Krawczak, P. (2013). Medical plastics: serving healthcare. Express Polymer Letters, 7(8), 651-651.http://dx.doi.org/10.3144/ expresspolymlett.2013.61.

17. Villanova, J. C. O., Oréfice, R. L., \& Cunha, A. S. (2010). Pharmaceutical applications of polymers. Polimeros: Ciência e Tecnologia, 20(1), 51-64. http://dx.doi.org/10.1590/S010414282010005000009 .

18. Severino, P., Santana, M. H. A., Pinho, S. C., \& Souto, E. B. (2011). Polímeros sintéticos biodegradáveis: matériasprimas e métodos de produção de micropartículas para uso em drug delivery e liberação controlada. Polímeros: Ciência e Tecnologia, 21(4), 286-292. http://dx.doi.org/10.1590/S010414282011005000060

19. Severino, P., Santana, M. H. A., Malmonge, S. M., \& Souto, E. B. (2011). Polímeros usados como sistemas de transporte de princípios ativos. Polímeros: Ciência e Tecnologia, 21(5), 361-368. http://dx.doi.org/10.1590/S0104-14282011005000061.

20. Saez, V., Ramón, J., Peniche, C., \& Hardy, E. (2012). Microencapsulation of Alpha Interferons in Biodegradable Microspheres. Journal of Interferon \& Cytokine Research, 32(7), 299-311. http://dx.doi.org/10.1089/jir.2011.0034. PMid:22774794.

21. Nkabinde, L. A. (2013). Poly (D,L-lactide-co-glycolide) nanoparticles: Uptake by epithelial cells and cytotoxicity. Express Polymer Letters, 8(3), 197-206. http://dx.doi.org/10.3144/ expresspolymlett.2014.23.

22. Hamad, K. (2015). Properties and Medical Applications of Polylactic Acid: A Review. Express Polymer Letters, 9(5), 435-455. http://dx.doi.org/10.3144/expresspolymlett.2015.42.

23. Ke, Y. (2014). Preparation of carboxymethyl cellulose based microgels for cell encapsulation. Express Polymer Letters, 8(11), 841-849. http://dx.doi.org/10.3144/expresspolymlett.2014.85.

24. Uhrich, K. E., Cannizzaro, S. M., Langer, R. S., \& Shakesheff, K. M. (1999). Polymeric systems for controlled drug release. Chemical Reviews, 99(11), 3181-3198. http://dx.doi.org/10.1021/ cr940351u. PMid:11749514.

25. Corrigan, O. I., \& Li, X. (2009). Quantifying drug release from PLGA nanoparticulates. European Journal of Pharmaceutical Sciences, 37(3-4), 477-485. http://dx.doi.org/10.1016/j. ejps.2009.04.004. PMid:19379812.

26. Letchford, K., \& Burt, H. (2007). A review of the formation and classification of amphiphilic block copolymer nanoparticulate structures: micelles, nanospheres, nanocapsules and polymersomes. European Journal of Pharmaceutics and Biopharmaceutics, 65(3), 259-269. http://dx.doi.org/10.1016/j.ejpb.2006.11.009. PMid: 17196803.

27. Pereira, E. D., Souza, F. G. Jr., Pinto, J. C., Cerruti, R., \& Santana, C. I. (2015). Synthesis, characterization and drug delivery profile of magnetic PLGA-PEG-PLGA/maghemite nanocomposite. Macromolecular Symposia, (in press)

28. Song, Z., Feng, R., Sun, M., Guo, C., Gao, Y., Li, L., \& Zhai, G. (2011). Curcumin-loaded PLGA-PEG-PLGA triblock copolymeric micelles: preparation, pharmacokinetics and distribution in vivo. Journal of Colloid and Interface Science, 354(1), 116-123. http://dx.doi.org/10.1016/j.jcis.2010.10.024. PMid:21044788.

29. Pereira, E., Souza, F. Jr., Santana, C. i., Soares, D., Lemos, A., \& Menezes, L. (2013). Influence of magnetic field on the dissolution profile of cotrimoxazole inserted into poly(lactic acid-co-glycolic acid) and maghemite nanocomposites. Polymer Engineering and Science, 53(11), 2308-2317. http://dx.doi. org/10.1002/pen.23606.

30. Ferreira, L. P., Moreira, A. N., Delazare, T., Oliveira, G. E., \& Souza, F. G., Jr. (2012). Petroleum absorbers based on CNSL, furfural and lignin - the effect of the chemical similarity on the interactions among petroleum and bioresins. 
Macromolecular Symposia, 319(1), 210-221. http://dx.doi. org/10.1002/masy.201100145.

31. Jeong, B., Bae, Y. H., \& Kim, S. W. (1999). Biodegradable thermosensitive micelles of PEG-PLGA-PEG triblock copolymers. Colloids and Surfaces. B, Biointerfaces, 16(1-4), 185-193. http://dx.doi.org/10.1016/S0927-7765(99)00069-7.

32. Li, Y., Pei, Y., Zhang, X., Gu, Z., Zhou, Z., Yuan, W., Zhou, J., Zhu, J., \& Gao, X. (2001). PEGylated PLGA nanoparticles as protein carriers: synthesis, preparation and biodistribution in rats. Journal of Controlled Release, 71(2), 203-211. http:// dx.doi.org/10.1016/S0168-3659(01)00218-8. PMid:11274752.

33. Wang, H., Zhao, Y., Wu, Y., Hu, Y. L., Nan, K., Nie, G., \& Chen, H. (2011). Enhanced anti-tumor efficacy by co-delivery of doxorubicin and paclitaxel with amphiphilic methoxy PEGPLGA copolymer nanoparticles. Biomaterials, 32(32), 82818290. http://dx.doi.org/10.1016/j.biomaterials.2011.07.032. PMid:21807411.

34. Qiao, M., Chen, D., Hao, T., Zhao, X., Hu, H., \& Ma, X. (2007). Effect of bee venom peptide-copolymer interactions on thermosensitive hydrogel delivery systems. International Journal of Pharmaceutics, 345(1-2), 116-124. http://dx.doi. org/10.1016/j.ijpharm.2007.05.056. PMid:17629639.

35. Saadati, R., \& Dadashzadeh, S. (2014). Marked effects of combined TPGS and PVA emulsifiers in the fabrication of etoposide-loaded PLGA-PEG nanoparticles: in vitro and in vivo evaluation. International Journal of Pharmaceutics, 464(12), 135-144. http://dx.doi.org/10.1016/j.ijpharm.2014.01.014. PMid:24451238.

36. Yang, A., Yang, L., Liu, W., Li, Z., Xu, H., \& Yang, X. (2007). Tumor necrosis factor alpha blocking peptide loaded PEGPLGA nanoparticles: Preparation and in vitro evaluation. International Journal of Pharmaceutics, 331(1), 123-132. http:// dx.doi.org/10.1016/j.ijpharm.2006.09.015. PMid:17097246.

37. Martín-Banderas, L., Muñoz-Rubio, I., Álvarez-Fuentes, J., Durán-Lobato, M., Arias, J. L., Holgado, M. Á., \& FernándezArévalo, M. (2014). Engineering of $\Delta$ 9-tetrahydrocannabinol delivery systems based on surface modified-PLGA nanoplatforms. Colloids and Surfaces. B, Biointerfaces, 123, 114-122. http:// dx.doi.org/10.1016/j.colsurfb.2014.09.002. PMid:25262411.

38. Jain, A., Jain, S. K., Ganesh, N., Barve, J., \& Beg, A. M. (2010). Design and development of ligand-appended polysaccharidic nanoparticles for the delivery of oxaliplatin in colorectal cancer.
Nanomedicine, 6(1), 179-190. http://dx.doi.org/10.1016/j. nano.2009.03.002. PMid:19447205.

39. Kelley, K., \& Lai, K. (2011). Accuracy in parameter estimation for the root mean square error of approximation: sample size planning for narrow confidence intervals. Multivariate Behavioral Research, 46(1), 1-32. http://dx.doi.org/10.1080/ 00273171.2011.543027. PMid:26771579.

40. Brownlee, K. (1984). Statistical theory and methodology in science and engineering. Malabar: Krieger Pub. Co.; 1984.

41. Corrigan, D., Healy, A., \& Corrigan, O. (2002). The effect of spray drying solutions of polyethylene glycol (PEG) and lactose/PEG on their physicochemical properties. International Journal of Pharmaceutics, 235(1-2), 193-205. http://dx.doi. org/10.1016/S0378-5173(01)00990-5. PMid:11879754.

42. Peppas, N. A., \& Narasimhan, B. (2014). Mathematical models in drug delivery: how modeling has shaped the way we design new drug delivery systems. Journal of Controlled Release, 190, 75-81. http://dx.doi.org/10.1016/j.jconrel.2014.06.041. PMid:24998939.

43. Ritger, P., \& Peppas, N. (1987). A simple equation for description of solute release I. Fickian and non-fickian release from nonswellable devices in the form of slabs, spheres, cylinders or disks. Journal of Controlled Release, 5(1), 23-36. http://dx.doi. org/10.1016/0168-3659(87)90034-4.

44. Jeong, J. H., Lim, D. W., Han, D. K., \& Park, T. G. (2000). Synthesis, characterization and protein adsorption behaviors of PLGA/PEG di-block co-polymer blend films. Colloids and Surfaces. B, Biointerfaces, 18(3-4), 371-379. http://dx.doi. org/10.1016/S0927-7765(99)00162-9. PMid:10915958.

45. Peppas, N., \& Sahlin, J. (1989). A simple equation for the description of solute release. III. Coupling of diffusion and relaxation. International Journal of Pharmaceutics, 57(2), 169-172. http://dx.doi.org/10.1016/0378-5173(89)90306-2.

46. Ritger, P., \& Peppas, N. (1987). A simple equation for description of solute release II. Fickian and anamolous release from swellable devices. Journal of Controlled Release, 5(1), 37-42. http://dx.doi.org/10.1016/0168-3659(87)90035-6.

Received: Aug. 14, 2015

Revised: Oct. 07, 2015

Accepted: Nov. 09, 2015 